\title{
The Rise of the U.S. Pecan Industry
}

Pecan [Carya illinoinensis (Wangenh.) C. Koch], preferentially pronounced as pi-'kän over pi-'kan or 'pe-,kan (Llewellyn, 1985), is one of the few native North American plant species that has been developed into a significant agricultural crop. It has also become one of the few indigenous U.S. food crops that is commercially cultivated outside the United States (i.e., Mexico, Australia, South Africa, Israel, Brazil, Argentina, Egypt, etc.). As perhaps the economically most significant native contributor to the U.S. agricultural economy, wholesale revenues approximate $\$ 200$ million annually (USDA, 1988), and approaches $\$ 400$ million when all aspects of the industry are included (Crocker, 1989).

Pecan is unique in that it is one of the few food crops in which a relatively detailed record exists concerning its cultivation and spread as an agricultural industry. The history of pecan husbandry therefore provides a unique glimpse, or case history, of this process and may potentially contribute valuable insight into understanding the initial domestication processes of more ancient crops and may aid in the domestication efforts of species that currently exist in the wild state. Domestication is a rather general term possessing broad-sense (being somewhat adapted to life in intimate association with and to the advantage of man) and narrow-sense (being sufficiently adapted so as to be devoid of significant deficiencies in relation to the traits judged by man to be important) subdivisions. In the botanical, or evolutionary, sense, pecan would be classified as relatively "undomesticated", because the cultivated genotypes are only slightly diverged from that of the wild type and would, therefore, be expected to possess the fitness necessary for survival in its natural environment. Humans have done a much better job adapting horticultural skills to meet the constraints of pecan germplasm than results achieved by altering the germplasm so as to produce a "botanically domesticated" crop. However, this semi-wild state of cultivated germplasm has not prevented the development and growth of a major industry. While the factors contributing to this growth were manifold, there were salient events that made this evolutionary-like process possible. The objective of this article is to present a brief introduction of pecan as a horticultural crop possessing a unique North American heritage, to briefly describe salient factors leading to the growth

Received for publication 28 Dec. 1989. The cost of publishing this paper was defrayed in part by the payment of page charges. Under postal regulations, this paper therefore must be hereby marked advertisement solely to indicate this fact.

Front cover: Example of nut variation exhibited by pecan. of the U.S. pecan industry, and to provide an overview of the current nature of the U.S. industry.

\section{FACTORS PROPELLING THE GROWTH OF THE PECAN INDUSTRY}

Factors and events molding the evolutionary-like changes relevant to the U.S. pecan industry are myriad and, subject to ones perspective, are debatable as to their relative importance. According to our general opinion, the following factors are the salient circumstances/events that have elevated pecan husbandry to today's status.

Quality product. Interest in pecan appears to have originated with the arrival of the aboriginal inhabitants of the Western Hemisphere to the major river systems of central and eastern North America (and possibly northeastern Mexico). Since pecan was readily accessible to waterways, and was generally regarded as among the best-tasting and easiest-to-shell of the 14 hickory (Carya spp.) species native to North America, it was heavily used and highly desired by precolonial residents. Its native habitat is the floodplains along the Mississippi, Ohio, Missouri, the Red rivers and their tributaries and along many of the largest rivers of eastern Texas and northeastern Mexico. During this era, the range of pecan appears to have extended from about lat. $42^{\circ} 20^{\prime} \mathrm{N}$ in the north (Bellevue, Iowa) to that of about lat. $16^{\circ} 30^{\prime} \mathrm{N}$ (Oaxaco, Mexico) in the south; however, the origin of the isolated pockets of pecans throughout most of Mexico is still being evaluated as to whether they were of natural or human origin.

The wide natural range and abundance of pecan led many Indian tribes inhabiting the United States and Mexico to use the wild pecan as a prized and major food source during the autumn (Baskett, 1960). One use of kernels was to produce a "cream-like" fluid that was used for cooking and drinking (Stuckey and Kyle, 1925); it also is alleged to have been used by some Indians to produce a fermented intoxicating drink termed "Powcohicora" (from which the name "hickory" was derived), which made the braves "braver" (G. Taylor, personnel communication; Stuckey and Kyle, 1925). Undoubtedly, this use also contributed to the nuts' popularity among the aboriginal inhabitants. In fact, the name pecan is an American Indian word of Algonquin origin that was used to designate "all nuts requiring a stone to crack" (Trumball, 1872, as cited by Stuckey and Kyle, 1925); however, it was also a Natchez Indian word specific for the plant we now know as pecan (McHatton, 1957). While a major food and trade item among American Indians (True, 1917), there is no record or evidence that they cultivated the tree. In fact, the first known cultivated plantings appear to have been by Spanish colonists and Franciscans in northern Mexico in the late 1600s or early 1700s (Ondernock, 1911 as cited by Flack, 1970 and Woodruff, 1967). These Mexican plantings appear to be documented to about 1711 , predating by $\approx 70$ years the earliest recorded planting in the United States.

The earliest known planting in what is now the United States was at Long Island, N.Y. in 1772 (McHatton, 1957). Nuts from the northern portion of the range reached the English-speaking area of the Atlantic Seaboard in the later 1700s, and were commonly planted in the gardens of notable easterners such as George Washington (1775) and Thomas Jefferson (1779) (True, 1917). During this time, settlers were also widely planting pecans in the gardens of communities along the Gulf Coast (Flack, 1970).

The economic potential of pecan had begun to be realized by the late 1700 s; especially by the French and Spanish colonists settling along the Gulf of Mexico. By 1802, pecan nuts gathered from wild trees had already become an article of commerce in the Mississippi Valley and were being exported by the French to the West Indies. Presumably, the nuts were exported to the West Indies and Spain much earlier by the Spanish colonists in northern Mexico.

Pecan's potential for cultivation was just beginning to be realized during this era. For example, it was advertised in London in 1805 that pecan was " . . . a tree meriting attention as a cultivated crop" (McHatton, 1957), and it was assumed that the success of cultivation attempts would hinge upon the responsiveness of pecan to clonal propagation techniques available at that time. However, its innate recalcitrance to clonal propagation may have delayed for several decades its cultivation.

Market. Prerequisite to the development of any crop is market demand and proximity. As a large port city, near the mouth of the Mississippi River, New Orleans was of great importance in the marketing of pecan (Flack, 1970). Since the Mississippi River, its tributaries, and east Texas rivers encompassed much of the natural wild pecan population, there was the availability of an abundant supply of the highly desirable wild nuts in close proximity to this large population center and port city. The city, therefore, provided a natural market and avenue for the redistribution of nuts to other parts of the United States and the world. This market potential fueled considerable local interest regarding the planting of orchards. This interest, in turn, stimulated an adaptation of clonal propagation techniques and led to the demand for grafted trees and for trees producing superior nuts. By the end of the 19th century, at least 15 commercial cultivars had been developed in the general region of Louisiana (Flack, 1970).

A second market of substantial importance was San Antonio, in eastern Texas, where it is reported that, in some years, the wild pecan crop harvested by farmers was more

(continued on p. 721) 
(continued from inside front cover)

valuable than row crops such as cotton. As in Louisiana, the demand for pecans in Texas also stimulated considerable interest in the development of pecan cultivars during the late 19th century (McHatton, 1959; T. Thompson, personal communication).

Clonal propagation. The American colonists had begun to acquire an understanding of the economic potential of pecan during the 1700 s and early 1800 s; therefore, pecan nuts had become an item of commerce and a small industry had been born. Interest in cultivating pecan did not proliferate until a solution was found to the problem of wide variability in nut quality and quantity. Since pecan groves (a collection of trees established by natural forces) and orchards (plantings established by humans) consisted of wild germplasm of diverse genotypes, plantings exhibited tremendous variability in nut size, shape, shelling characteristics, flavor, fruiting age, and ripening date. This variability presented major obstacles to commercial cultivation and thus limited the commercial value of pecans.

This substantial variability among trees resulted in the occasional discovery of a wild tree with unusually large, thin-shelled nuts. Nuts from such trees were especially valued and in high demand by consumers and were recognized as a key to making money with pecans (Crane et al., 1937). While it was recognized by the early 1800 s that the establishment of orchards with clonal material would solve problems with variability and nut size and shelling characteristics, there had not yet been a successful adaptation of clonal propagation techniques already known to be successful on certain other woody crops. However, in 1822, Abner Landrum of South Carolina published that he had developed a highly successful pecan budding technique. This discovery provided, for the first time, the opportunity to establish clonal plantings derived from superior wild selections rather than the diverse polygenetic plantings used up to that time. This development, in turn, created an opportunity to avoid the many cultural and marketing liabilities common to polygenetic planting. Unfortunately, this breakthrough was either lost or neglected and was not used again until the 1880s. It was not until 1846 that the clonal propagation of pecan began to be used. In 1846, a slave gardener named Antoine (owned by Governor Telesphore J. Roman, Oak Alley Plantation, La.), successfully propagated pecan by grafting a superior wild pecan (found by A.E. Colomb) to seedling pecan stocks (Stuckey and Kyle, 1925). This clone was eventually named 'Centennial' because it won the "best pecan exhibited" at the Philadelphia Centennial Exposition in 1876. This planting, of what was to become 126 'Centennial' trees, became the first known commercial clonal pecan orchard and was the first planting of improved pecans.

The successful adaptation of grafting techniques eventually led to the establishment of clonal orchards of superior genotypes and was a critical milestone in attempts to use pecan as a cultivated crop (Bailey, 1922). Al- though a major technical breakthrough in pecan culture, this propagation technique developed by Antoine was slow to be adopted by others and had little commercial impact until the 1880s, when nurserymen in Louisiana and Texas learned of pecan grafting and began clonal propagation on a commercial scale.

Gulf coast freeze. Another factor that accelerated cultivation was the destruction of citrus orchards along the Gulf of Mexico. Devastating freezes hit in the winters of 188687 and again in the winters of 1894-96, resulting in a generalized decimation of citrus orchards. In an attempt to find an alternative crop, much of this land was replanted with pecan, thus providing a demand for nursery stock in portions of the coastal region (Flack, 1970).

In addition to the initial intense interest around New Orleans, interest in pecan cultivation had spread to four other regions during the late $1800 \mathrm{~s}$, all of which were either on the fringe of the natural range or outside of it. These regions were southern Mississippi, northern Florida, southern Georgia, and the upper Colorado River of central Texas (Flack, 1970). The relatively concurrent events of the severe freezes and the introduction of clonal trees resulted in a substantial demand for the superior nursery-produced trees. Commercial nurseries soon followed in Florida, Georgia, Mississippi, and Texas.

This demand for nursery stock led to trees" becoming very expensive $(\$ 2.50$ per plant during the 1880s) and difficult to obtain; therefore, most pecan plantings established between 1870 and 1900 used open-pollinated seed (even though most people apparently recognized that pecans probably did not come absolutely true from seed). These seedling orchards, many being several hundred hectares, were widely planted throughout the central and southern states, especially in areas bordering the Gulf of Mexico. The inadequate supply of improved trees began to be alleviated in the 1890s when E.E. Risien of San Saba, Texas, successfully adapted a ring budding technique and thus popularized the potential for this technique for pecan and vastly enhanced the grower's ability to obtain superior clonal materials. The result was a decline in the price of nursery stock and the introduction of clonal cultivars originating from superior wild trees. Such cultivars were 'Stuart', 'Van Deman', 'San Saba', 'Moneymaker', 'Columbia' (or 'Rome'), 'Delmas', 'Frotscher', 'Kennedy', 'Schley', etc.; several of these are commonly found in contemporary commercial orchards.

Seedling selections. Another factor having major significance for the use of pecan was the interest exhibited by several growers in southern Mississippi (Jackson County, which was outside the native range of pecan) and eastern Texas. Several seedling orchards and nurseries were started from 1874 to about 1900. Early growers observed occasional seedling trees that bore large, thin-shelled (commonly termed papershells) nuts. Such trees were clonally propagated and sold throughout the states bordering the Gulf of
Mexico as interest in pecan increased. Out of this area came the cultivars that dominated orchard plantings throughout most of the next century. Even today, many cultivars developed in Jackson County, Miss. (KenKnight, 1970) and in central Texas (Burkett, 1932) are considered to be the standards of the industry. Such cultivars as 'Stuart', 'Desirable', 'Western', and 'Schley' continue to be the major cultivars produced in the industry, with 'Stuart', 'Desirable', and 'Western' still being highly recommended for new plantings (Thompson, 1984). One grower, a Mr. Forkert, became the earliest known pecan breeder (1903) and consequently produced several good cultivars (Crane et al., 1937; Risien, 1904). One of these was 'Desirable', which is currently considered to be the best cultivar for commercial cultivation in the southeastern U.S. environment. Similarly, E.E. Risien, a grower from San Saba, Texas, began breeding pecan in 1904 and eventually produced 'Western Schley' (the standard of the western sector of the U.S. pecan belt). He eventually produced numerous cultivars and was a major factor in the popularization of pecan in Texas and the western United States (Crane et al., 1937).

Era of speculation. The era of the 1890s to 1930 s was a time when many existing seedling orchards and groves were top-worked to establish improved cultivars (large and easyto-shell nuts became the predominant criteria for improvement). The vast majority of these scion cultivars were from someone's favorite wild tree. The owners frequently gave the clone their own surname or their spouse's name and attempted to market clones with what would later prove to be an insufficient regard for proven horticultural characteristics. This practice resulted in the introduction of several hundred named cultivars (Crane et al., 1937). During this era, there was also an extensive proliferation of orchards in southwestern Georgia (an area well outside the specie's native range) and in east-central Texas. This proliferation appears to have been due to a spirit of speculation that began about 1900 and arose as a result of: a) low land prices due to problems with cropping cotton; b) exaggerated reports of wealth from cropping pecan; and c) in the case of Georgia, an abundance of northern retirees believing sales propaganda advocating a comfortable retirement from the revenue produced from a few hectares of pecans (McHatton, 1957; Stuckey and Kyle, 1925). The result was a speculative fervor and flurry of get-rich-quick schemes in which orchards were planted and quickly sold with a promise of wealth to the new owner. Thousands of hectares were planted with the purpose of making money through selling orchards rather than through selling the crop. Since there appear to have been frequent misrepresentations of facts and a deficiency of adequate horticultural, pathological, and entomological information, this speculative fervor soon resulted in many unproductive orchards and a subsequent initial decline in the popularity of the crop.

Because of this period of speculation, there was a major change in the nature of the 
evolving industry. The former region of major production had been eastern Texas and Louisiana (native nuts) and southern Mississippi (seedlings); however, major production potential was now established in southwestern Georgia [Georgia currently accounts for $\approx 36 \%$ of the total U.S. pecan production and $\approx 48 \%$ (or $53 \%$ when one adds in yard trees that are cultivars) of the production from cultivars] (USDA, 1988). Many of these hastily established orchards in the southeast rapidly became unprofitable and were initially abandoned because of an inability of growers to control pecan rosette (induced by $\mathrm{Zn}$ deficiency).

Chemicals. The recovery of the industry from the nutrition-related disappointments of the 1920s and 1930s was largely due to the discovery that pecan rosette could be corrected by fertilization with Zn (Sparks, 1987). This breakthrough stimulated great interest in renewing cultivation of abandoned orchards and the planting of new ones. While new trees continued to be planted between 1935 and the 1960s, the intensity of activity was far less than during the first quarter of the 20th century. The chemical control of insect pests, such as hickory shuckworm, pecan weevil, aphids, pecan nut casebearer, etc., have also made a major contribution in allowing for industry expansion, especially with the availability of air-blast spray equipment that allow for rapid and economical control of insect and disease pests. These nutritional- and pesticide-related advances resulted with considerable emphasis being placed on reviving and invigorating previously established but abandoned orchards.

The increase in pecan production in Georgia from 1970 to 1983 is reported to be "associated with the onset of widerspread spraying to control insects and diseases and progress in correction of nitrogen, potassium, magnesium, and zinc shortages" (Sparks, 1983). Sparks (1983) also indicated that a further "increase was associated with extensive use of irrigation, generally good sunlight conditions, and the additive efforts of these factors when combined with insect and disease control and improved nutrition". These improvements in cultural and management strategies had the end effect of retaining leaves in a relatively high state of efficiency, hence maximizing assimilate accumulation and a subsequent moderation of alternate bearing and enhancing yield. Our experience supports this observation, not only for Georgia, but also for the southeastern section of the U.S. pecan belt (Wood, 1989; Wood et al., 1989).

Improved cultivars. This most recent growth phase of the pecan industry began in the late 1960s and spans to the early 1980s. During this era, additional hectares of pecan orchards were not only established in the traditional pecan-growing areas, but were also established in the arid west, far removed from the natural range of the species. Many thousands of hectares of trees (mostly "Western Schley') were planted in western Texas, New Mexico, Arizona, and California, thus extending the commercial pecan belt across the entire southern United States from North Carolina to California. This expansion was primarily due to the recognition that the demand for pecans had not yet been satisfied; however, the availability of highly precocious and prolific new cultivars from the USDA/ARS pecan breeding program (due to the breeding, evaluation, and promotion efforts of L. Romberg and G. Madden) also appears to have stimulated interest. Production from these relatively young trees and an increase in production from existing mature trees in the southeast (due to greater attention to sound horticultural practices, especially those practices that minimize alternate bearing) have been major factors in catapulting pecan production and economic worth to to- day's relatively high level and has elevated pecan to that of being a valuable and unique contributor to the U.S. economy.

United States pecan production has grown rapidly during the past 100 years, with initial production being predominantly seedling nuts produced from native' or seedling trees until about 1958, when production from cultivars equaled that of seedlings (Fig, 1). Production of nuts marketed from cultivars is continuing to rise, whereas those from seedlings have been slowly dropping since 1963 (USDA, 1987). The demographics of the U.S. commercial pecan production is such that $\approx 75 \%$ of the national production is from the humid southeastern quadrant of the country (Table 1), with about $46 \%$ of total produc-

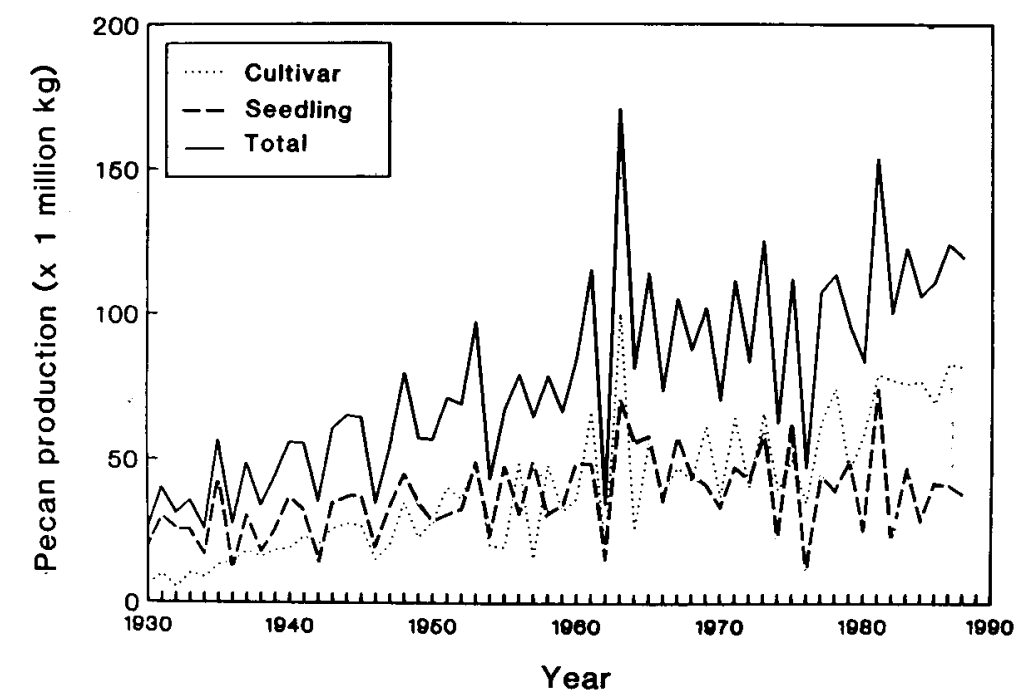

Fig. 1. Time-trend for the production of cultivars, seedling, and total in-shell pecan nuts in the United States.

Table 1. Average commercial in-shell U.S. pecan production by major producing states. Production is for the period from 1982-1988. The 6 years cover three alternate bearing cycles, hereby giving representative comparisons.

\begin{tabular}{|c|c|c|c|c|c|c|}
\hline \multirow[b]{3}{*}{ State $^{y}$} & \multicolumn{6}{|c|}{ In-shell pecan production (millions of $\mathrm{kg}$ ) } \\
\hline & \multicolumn{2}{|c|}{ Cultivars $^{x}$} & \multicolumn{2}{|c|}{ Seedlingsw } & \multicolumn{2}{|c|}{ Total } \\
\hline & (wt) & $(\%)^{v}$ & $(w t)$ & $(\%)^{\mathrm{y}}$ & (wt) & $(\%)^{\mathrm{t}}$ \\
\hline Alabama & 5.1 & 5.4 & 2.6 & 7.2 & 7.7 & 5.9 \\
\hline Arizona & 9.1 & 9.7 & 0.0 & 0.0 & 9.1 & 7.0 \\
\hline Arkansas & 0.5 & 0.5 & 0.2 & 0.6 & 0.7 & 0.05 \\
\hline California & 1.7 & 1.8 & 0.0 & 0.0 & 1.7 & 1.3 \\
\hline Florida & 1.0 & 1.1 & 1.0 & 2.8 & 2.0 & 1.5 \\
\hline Georgia & 42.7 & 45.7 & 7.1 & 19.6 & 49.8 & 38.4 \\
\hline Louisiana & 1.3 & 1.4 & 7.2 & 19.8 & 8.5 & 6.6 \\
\hline Mississippi & 2.2 & 2.4 & 1.2 & 3.3 & 3.4 & 2.6 \\
\hline New Mexico & 12.1 & 12.9 & 0.0 & 0.0 & 12.1 & 9.3 \\
\hline North Carolina & 0.5 & 0.5 & 0.6 & 1.6 & 1.1 & 0.8 \\
\hline Oklahoma & 0.6 & 0.6 & 5.9 & 16.2 & 6.5 & 5.0 \\
\hline South Carolina & 5.9 & 6.3 & 0.6 & 1.6 & 6.5 & 5.0 \\
\hline Texas & 10.8 & 11.6 & 9.9 & 27.3 & 20.7 & 16.0 \\
\hline Total & 93.5 & & 36.3 & & 129.8 & \\
\hline
\end{tabular}

"Production date from 1989 USDA Agricultural Handbook on "Agricultural Statistics". Data on Ari. zona is an estimate provided by the Cooperative Extension Service.

These are the primary commercial states. Limited commercial production is also in Missouri, Kentucky, Kansas, Illinois, Tennessee, Virginia, and Iowa.

"Cultivars" means nuts identifiable as a particular quality cultivar when sold.

'Seedlings consist of nuts from nonclonal trees, nuts from seedling or native groves, and cultivars not identifiable as a quality cultivar when sold.

"Percent of national total of "cultivar" nuts.

"Percent of national total of "seedling" nuts.

'Percent of total U.S. production. 
tion being within a 200-km radius of Albany, Ga. Three-fourths of total commercial production is from the five states of Georgia (38\%), Texas (16\%), New Mexico (9\%), Arizona (7\%), and Louisiana (7\%). The bulk of improved cultivars are primarily produced from Georgia (46\%), New Mexico (13\%), Texas (12\%), and Arizona (10\%).

While the U.S. pecan industry has evolved to a level of economic significance, it has recently encountered a substantial barrier to its continued growth. This barrier is a "costprice squeeze" that is beginning to force many growers and shellers out of business. The squeeze is primarily due to a historical failure of the industry to act in a concerted group effort to develop and expand markets. While the industry has now begun to address this problem, it appears that there will be another 10 or more years before the industry will be able to enjoy the profitability of its former years.

\section{Literature Cited}

Bailey, L.H. 1922. Pecan. The standard cyclopedia of horticulture. vol. .5. Macmillan, New York. p. 2513-2517.

Baskett, J.N. 1906. A study of route of Cabeza de Vaca. Texas Hist. Assn. Quart. 1:10-17.
Burkett, J.H. 1932. The pecan in Texas. Texas Dept. of Agr. Bul. 111.

Celiz, F.F. 1935. Diary of the Alarcon expedition into Texas, 1718-1719. Quivira Soc. Pub. 5:1221. (Trans. by F.L. Hoffman.)

Crane, H. L., C.A. Reed, and M.N. Wood. 1937. Nut breeding. USDA Yrbk. 1590:827-890.

Crocker, J. 1989. Pecan promotion research act. The Pecan Grower 1:1, 3 .

Flack, J.R. 1970. The spread and domestication of the pecan in the United States. PhD Diss. Univ. of Wisconsin, Madison.

Llewellyn, W.T. 1985. Webster's ninth new collegiate dictionary. (F.C. Mish, Ed.-in-Chief). Merriam-Webster, Springfield, Mass.

KenKnight, G. 1970. Pecan varieties "happen" in Jackson County, Mississippi. Pecan Quart. 4(3):6-7.

McHatton, T.H. 1957. The history, distribution and naming of the pecan. 50th Proc. Southeastern Pecan Growers Assn. p. 10-34.

Risien, E.E. 1904. Pecan culture for Western Texas. (Published by the author.)

Sparks, D. 1983. Alternate fruit bearing in nut trees. Annu. Rept. Northern Nut Growers Assn. 74:197-230.

Sparks, D. 1987. Apparent effect of zinc treatment on the growth rate of pecan production and yield. HortScience 22:899-901.

Stone, D.E. 1962. Affinities of the Mexican endemic Cmya palmei with American and Asian hickories. Amer. J. Bet. 49:199-212.
Stuckey, H.P. and E.J. Kyle. 1925. Pecan growing. Macmillan, New York.

Thompson, T. 1984. Pecan cultivars: Current use and recommendations. Pecan Quart. 18:20-26.

True, R.H. 1917. Notes on the early history of the pecan in America. Annu. Rpt. Smithsonian Inst. p. $435-448$

U.S. Department of Agriculture. 1988. Agricultural Statistics. U.S. GPO, Washington, D.C.

Wood, B.W. 1989. Nut yield of pecan as affected by root carbohydrate and rootstock. J. Amer. Soc. Hort Sci. 114(2):223-228.

Wood, B. W., W.L. Tedders, and C.C. Reilly 1988. Sooty mold fungus on pecan foliage suppresses light penetration and net photosynthesis. HortScience 23(5):851-853.

Woodroof, J.G. 1967. Pecan history and distribution. Tree nuts: Production, processing, products. vol. 2. AW, Westport, Corm. p. 138.

BRUCE W. WOOD and JerRy A. PAyne Agricultural Research Service, U.S. Department of Agriculture, Southeastern Fruit and Tree Nut Laboratory,

P.O. Box 87, Byron, GA 31008

LARRY J. Grauke

U.S. Department of Agriculture, Pecan Genetics Laboratory, Somerville, TX 77879 